\title{
Instrucciones para no morir incinerado
}

\author{
Instructions not to die incinerated
}

\section{I}

$\mathrm{B}$ ienvenido. Siempre llegue temprano a la biblioteca. Si no se justifica su retraso con su grabación ocular puede ser sancionado o, incluso, hallado culpable de sospecha de traición. No lo olvide. Últimamente todos los ministerios, registros y tribunales se han convertido en bibliotecas o enormes archivos. Después de sobrevivir a la Gran Guerra todos hacemos labor de clasificar y destruir información, o bien, reescribirla. ¿Por qué? No debería preguntar, ya lo sabe. No hay necesidad de saber más de lo que el Alto Mando le ha ordenado que sepa. Señor Víctor, esperamos que se aboque a sobrevivir y perpetuar el legado del Alto Mando, como lo dice la consigna de este.

Apéguese a las órdenes programadas en su chip de memoria; no intente pensar más allá de lo que no se le ha pedido en su programación matutina. Muchos cometen el error de analizar lo que deben hacer. Solo debe seguir sus instrucciones. El chip de memoria registra sus pensamientos y los envía a
Ronald Gerardo Hernández Campos

los satélites del Alto Mando. Si piensa demasiado sus órdenes, el chip enviará la orden de que su cuerpo sea incinerado en el acto.

Todos los días, una vez que ha llegado a las oficinas centrales de su despacho, por medio del brazalete de control, conéctese a la red de su departamento de incineración de la Biblioteca Nacional y no se guarde libros, facsímiles ni ninguna información desclasificada. Recuerde que si es bibliotecario, debe leer, clasificar y catalogar todo lo que será vuelto a escribir; todo material escrito anterior a la época de la Tercera Gran Guerra.

\section{II}

El día que desperté, asumo que luego de la Gran Guerra (no sé, a ciencia cierta), todo había terminado ya, o al menos lo que yo recordaba. No había nada que yo reconociera. Desperté en una especie de clínica-laboratorio, con un montón de personas aún dormidas en lo que parecían ser cápsulas; 
yo siempre he creído que eran ataúdes. Lo primero que escuché cuando desperté fue una especie de alarmas. Tenía varios cables y pulsos eléctricos atados al cuerpo. Lo que parecían ser doctores, enfermeras y asistentes se acercaron a mí con sus bitácoras. Estable, pulso normal, no presenta daño cerebral. No hay anomalias, funciones neuronales estables. Todo en orden, está listo, funciona. Palabras sin sentido para mí.

- ¿Puede hablar; puede entenderme? -me dijo una muchacha con bata blanca, lentes, cabello castaño, quien fue la única que se quedó del grupo que vino a verme.

-¿Ganamos?...-fue lo que me salió de inmediato.

-¿Quiénes?

-Nosotros... iganamos la guerra?

-iAh, la guerra! El Alto Mando ahora está a cargo de los satélites, de los chips de memoria y de las operaciones de limpieza, catalogación, desclasificación y reescritura de la información.

-Pero ¿qué pasó con los demás países... las armas de destrucción masiva?

-Señor Víctor, nadie recuerda ya eso. A ustedes se les irá explicando conforme el Alto Mando los requiera para sus nuevas labores como los bibliotecólogos del Estado. Espere unos instantes a que se active del todo su chip de memoria con las indicaciones.

-¿Qué debo esperar... que se active qué...?

Un dolor de cabeza intenso; mi cabeza arde por dentro; en el sitio de la nuca, siento como si me fuera a explotar algo. No logro contenerme. Lo que asumo que ha estado alimentándome hasta mi despertar ya salió por ambos lados. Vomito. Grito de dolor; la mujer frente a mí, por lo que alcanzo a ver, solo se limita a escribir en su bitácora y al parecer graba lo que ve con un aparato que no reconozco bien. El dolor va cesando, la sensación de ardor se normaliza.

- ¿Se encuentra bien, señor Víctor? - es lo único que a la mujer se le ocurre preguntarme. No logro contestarle nada, tengo la boca entumecida, adolorida; asiento con la cabeza. Ella prosigue:

-Todo está dentro del rango de lo normal. No se preocupe $\mathrm{y}$, más que todo, no piense cosas innecesarias. $\mathrm{Cu}$ ando escuche en su cabeza y vea en su ojo derecho sus instrucciones, diríjase a la biblioteca que le corresponde para su asignación de labores. Evite pensar más de lo necesario, o será incinerado de inmediato.

\section{III}

Utilice los escáneres de mano del brazalete de control para leer los documentos y libros en su despacho. Solo debe girar la muñeca frente a la página que deba leer. De inmediato se cargará la información del texto. El chip de memoria le indicará qué debe hacer con cada libro y documento analizados. Solo hay tres opciones, para lo cual tiene tres ventanillas frente a su escritorio. Cada ventanilla antecede una banda transportadora. Destruir, archivar, reescribir. Casi nada se archiva. El chip no le dará esta opción, más que en uno de cada cien documentos. Es algo casi imposible. ¿La razón? No es algo que le corresponda saber, señor Víctor.

No debe guardar ninguno de estos libros, documentos o facsímiles. Incluso debe escanear objetos que encuentre en su despacho. Todo documento que sea sustraído de los despachos 
de la biblioteca, y que además sea leído con la vista y no con el escáner, significa una sentencia de muerte para el funcionario. ¿Por qué? No necesita saberlo, es una muestra de alta traición. Sí, señor. Es todo lo que debe saber. Debe apegarse al itinerario, ya que constantemente se están sacando nuevos embarques de documentos.

Debe recordar que, si encuentra documentos $\mathrm{u}$ objetos que no están incluidos en su catálogo, debe reportarlos y un inspector general de la biblioteca llegará a inventariarlo. Como comprenderá, señor Víctor, está siendo vigilado tanto por su chip de memoria, GPS, como por las múltiples cámaras que hay dentro del edificio de la biblioteca. La libertad vigilada es otra de las consignas del Alto Mando que usted debe custodiar.

\section{IV}

Yo nunca esperé terminar mis días encerrado en una biblioteca. He podido encontrar documentos que recuerdo que se usaban en la época cuando la Gran Guerra estalló. Todo es muy confuso. Periódicos que deben ser borrados de la historia. Libros que en otro tiempo se consideraron reliquias, clasificados, reescritos o vueltos nada. Papeles que correspondían al entonces régimen democrático, o al menos eso recuerdo vagamente. Nunca entendí bien qué era nuestro pueblo con exactitud. El hombre que nos usó como su ejército hoy es conocido con otro nombre y forma parte del Alto Mando. No sé cuándo se acabó la Guerra, ni qué ocurrió. El mundo que conocí se acabó aproximadamente hace cincuenta años (estoy en el siglo XXIII).
Ver los papeles que utilizábamos en mi entonces no es más alentador que escanearlos y que mi cerebro recomiende destruirlos o reescribirlos. Nombres de personas, borrados de la historia. Personas que nunca existieron, creadas para alguna función heroica o de mártir. En mi cerebro solo escucho y veo las palabras destruir, reescribir. No he visto conservar. Llevo aquí apenas un par de días, desde que desperté. De todo lo que he escaneado, solo hay un libro que me llamó la atención, pero es de una época muy anterior a la Gran Guerra.

Yo no sé de cuándo pudo haber sido, ya que yo nací un siglo después, según puedo ver en la ficha de catalogación. Aunque el escáner lo reconoció de inmediato y me desplegó información y la orden de esperar a un inspector general, no ha venido nadie a buscarlo para reclasificación y saber qué hacer con él. Puedo sentir calentarse mi nuca: el chip debe estar analizando el hecho de que estoy pensando en abrir el libro. Sé que es mi sentencia de muerte, pero, luego de ser instruido en las consignas del Alto Mando, comprendí que desde que fui despertado de la cápsula ya estaba anulado.

\section{V}

No, señor. Una vez que usted es asignado como bibliotecólogo, su programación no puede cambiar. Tampoco es posible, señor Víctor. Usted, como los demás funcionarios, vive en el subsótano del despacho de su biblioteca. Sí, señor: una vez al mes puede salir de aquí. Jamás, nunca debe volver a preguntarlo, ya que se coloca en una posición comprometedora, y no debo 
repetir los que usted me acaba de referir. Es prohibido, señor Víctor, que vuelva a preguntar por información sobre lo que pasó durante y posterior a la Tercera Gran Guerra... no, no debe guiñar el ojo derecho.

El funcionario que me entrenaba dejó caer un papel, cuando siguió su camino al despacho y me dejó en el mío con el montón de libros, papeles y objetos de épocas pasadas; muy probablemente lo escribió en algún momento mientras me daba todas las indicaciones de mi asignación de labores. Todo el tiempo tuvo una bitácora y un libro en sus manos. De vez en cuando, no lo noté, escribía cosas cuando yo le hacía preguntas, y al parecer en una parte de algún libro que ya ha sido destruido... al igual que mi instructor. Como pude, leí solo con el ojo derecho.

Limitese a entender que usted y yo solo somos un vestigio del pasado puesto en funcionamiento por un capricho del Alto Mando... Todos los que usted conoció, que fueron soldados, que formaron parte de la revolución que involucró al mundo entero, ya fueron reubicados, utilizados, muchos ya fueron convertidos en cenizas como estos libros y papeles... lo que yo recuerdo, lo que usted recuerda, muy probablemente sea una mentira. No sé la razón por la que despertamos, si se supone que nosotros no existimos. Estamos muertos... pude burlar el chip, el sobrecalentamiento de la parte del bulbo raquídeo, creo que nuestros antepasados lo llamaron asi... nos utilizan para borrar la historia... para arreglar lo que hicieron... para que los sobrevivientes y la nueva cúpula del Alto Mando se perpetúen hasta el fin de los tiempos... no hay escapatoria: ya estamos muertos. El chip. Los escáneres. El brazalete y la red.
Todo se dirige a los satélites. Nadie está a salvo. Todos podemos ser encontrados. No se puede huir de los inspectores generales. Cuando encuentre algo que no está catalogado, considérese hombre muerto... destruya esto antes de que se active la alarma... y siga la labor que se le ordenó... esta página era de una revista que contaba por qué los lideres del Alto Mando provocaron la última Gran Guerra y cuando por fin utilizaron los motores de plasma para crear armas más poderosas de lo imaginable, destruyeron a todas las potencias que les opusieron... nosotros somos un resabio del pasado, porque somos cuerpos de soldados congelados y utilizados como recipientes vacíos, con mentes borradas... nadie sabe que existimos y que hacemos el trabajo sucio de los lideres: dejar de recordar que destruyeron al mundo con el mismo capricho con el que hicieron uno nuevo para lograr que...

Mi instructor no fue muy comunicativo. No terminó su relato. Lo entendí todo. La comunicación del chip con la red, con el satélite, se interrumpe brevemente cuando se cierra el ojo derecho. No comprendí mucho de lo que decía su nota, pero sabía que no había mucho tiempo. El libro que encontré, el haber cerrado el ojo derecho por tanto tiempo. Pronto vendrían por mí. Decidí cerrar la entrada y leer en el poco tiempo que me quedaba. De todas maneras, como mi instructor, yo ya estoy muerto. Nadie nunca sabrá que en realidad existí. Ni siquiera sé con certeza que me llamo Víctor.

El libro es de un tipo de papel que se dejó de fabricar en el siglo XXI. Está escrito en caracteres de una antigua lengua que se enseñó incluso en tiempos de la Gran Guerra, cuando 
todavía se podía hablar de las diferentes potencias mundiales, hoy solo sectores del 1 al 5, gobernados por el Alto Mando, quienes además, según lo que he podido ojear, con armas y motores a base de plasma lograron dominar en menos de cinco años el mundo entero, derretir los polos y ahogar a las tres cuartas partes de la población; el objetivo real era...

\section{Epílogo}

-El objetivo fue eliminado. Incinerado, junto con el libro. Sí, señora. Otro experimento fallido. Será reemplazado por el siguiente experimento. Esperen a que la próxima cápsula reanime al siguiente... - dijo uno de los inspectores generales de la Biblioteca Nacional que entró sin ningún esfuerzo al lugar donde se escondía Víctor.

Por el intercomunicador del brazalete de control la mujer de pelo castaño, lentes y bata blanca se lamentaba. El proyecto de reanimación de soldados sería cancelado. Incinerar a los restantes y empezar de cero. Órdenes del Alto Mando.

\title{
El desconocido
}

\author{
The unknown
}

Para C. Agustín Arguedas Dávila...

En una época como la nuestra, por demás está decir que era normal que desaparecieran personas y que luego encontraran sus cuerpos en algún campo o construcción abandonada, incluso en automóviles que nadie había visto moverse jamás y que llevaban toda la vida de estar tirados en los poblados. Un caso muy interesante fue el del hallazgo de tres cuerpos sin cabeza, en distintas partes de San José... El periodismo amarillista y los sucesos de diario.
Para Charly, la violencia no era normal. Los homicidios lo aterraban (tal vez le temía a la muerte, como cualquiera); le tenía miedo a cualquiera que le alzara la voz o se pusiera un poco matón. Leer estas noticias no era nada alentador, pero era con lo que las redes sociales lo bombardeaban.

No creía en los horóscopos. No creía en el destino. Era el típico chico de veintitantos que recién terminaba una carrera (ingeniero de sonido con un sueño), también era músico - artista sensible a todas luces -, amante del 
rock, bajito de estatura, cabello castaño claro (tirando a rubio), de tez blanca con un poquito de acné, barba apenas visible: completamente diferente a la estética esperable y a los gustos de un país tropical con sus mitos arraigados en las culturas más occidentales, pero de etnias más amerindias de lo que podría llegar a admitir, en realidad. Charly no era bueno ligando (traumas de la niñez, falta de seguridad, él y su mundo, detalles, detalles, cosas sin importancia); abrió un perfil en una de esas redes sociales para conocer chicos.

Alguien interesante - bastante interesado en él- respondió a su mensaje: el "hola" reglamentario, junto con foto de cara, había rendido frutos. Se llamaba Roy, parecía ser todo lo contrario a él: alto, moreno, velludo, de ojos y sonrisa pícara, una barba que hizo a Charly pensar en más cosas debajo del bóxer de Roy. Se vieron. Se gustaron. ¿Flechazo? ¿Amor a primera vista? No era claro en ese momento, pero Roy se le presentó como el hombre más atento y cariñoso que se le habría presentado en mucho tiempo (el pequeño Charly estaba cansado de besar sapos en busca del príncipe).

El jefe policial dijo que los cuerpos estaban envueltos en sábanas y expresó que hay un cierre de calles en los alrededores, mientras se da el levantamiento de los cuerpos. Versiones extraoficiales indican que los cuerpos presentan lesiones en el cuello, aparentemente con alambres... Las noticias no dejaban de hablar del caso, ya que los hallazgos en los meses posteriores arrojaban datos poco claros para la investigación: no se llegó a concluir si el modus operandi del asesino correspondía a un ajuste de cuentas, o era un asesino en serie como el Psicópata, o era una banda que se dedicaba a los ajusticiamientos. Para Charly, como para muchos, era algo que no deseaba discutir o pensar siquiera, principalmente porque en "el país más feliz del mundo" la muerte de los compatriotas era algo que se podía obviar con la misma indiferencia con que se miran los demás sucesos macabros, con la idea de "eso por dicha no me pasará, así que ¡chill!”...

Roy nunca le había dado a Charly ningún motivo de queja desde que se conocieron: el novio atento, detallista, amable, cariñoso, algo morboso- lo cual Charly disfrutaba-y sobre todo el detalle que le dio más por el lado correcto para que aflorara el amor: Roy era un amante de muchas bandas de rock que para el pequeño Charly eran casi que de culto. Para los amigos de Charly, por el contrario, Roy parecía muy excéntrico, en realidad: demasiado bueno para ser soltero, o muy atento con el pequeñín para ser en verdad alguien común y corriente. Incluso un compa medio esotérico (la loca de Samuel) le habló de que su aura le daba mala espina, lo dejaba desconcertado. Charly ignoró a todos, principalmente a Samuel: no creía en horóscopos, menos en el destino o las auras.

Roy también era muy atento de que su pequeño novio estaba contento con él; incluso, decidió que era el momento para ir al siguiente paso: después de tres meses, dormir juntos en su apartamento. La propuesta ideal para que Charly al fin se quedara con él: un concierto. Charly aceptó encantado. Roy nunca le había dado motivos de desconfianza. Después de varias horas de concierto, llegaron al apartamento de Roy. Todo estaba preparado para una velada romántica: una cena ligera, velas, la cama perfumada. Ambos se desvistieron y se dieron un beso largo. 
Luego, muy entrada la noche, Charly por fin había caído rendido, después de la euforia nocturna del concierto y demás cosas que un par de novios harían solos en su apartamento. Apagaron las luces e hicieron el amor: Charly perdería algo más que la virginidad... Lo desconocido es una de las cosas más escalofriantes que hay, Charly sólo pensó en esto al despertar (un sueño extraño lo había inquietado durante la noche). No había notado los espejos en la habitación hasta que clareó en la mañana y se despabiló a medias. No había abierto bien los ojos, pero al ver por el espejo la mano de Roy que lo rodeaba, notó el cuchillo que sostenía y que esta era o estaba un poco más pálida (o demasiado pálida, considerando que Roy era moreno).

Decidió voltearse un poco, sigilosamente, para no despertar al amado y contemplarlo más detenidamente: lo vio de reojo, pero no era Roy: era un hombre más pálido que blanco, en realidad, con la barba, con el arqueado de las cejas (un tanto pobladas ahora que lo notaba), con la sonrisa del que creía su novio, pero a fin de cuentas no era él. ¿Era de verdad Roy? ¿Con quién había dormido en verdad? Nunca debió salir de su casa, nunca debió mentirle a su madre de que pasaría la noche con una amiga... Pensó también, intentando contener los gritos, en cómo huir de los brazos de ese otro extraño que no era a quien se había entregado en la noche, aunque ya era muy tarde: el hombre al que había acompañado al concierto, con el que había amanecido, no parecía ser Roy: era completamente otro, olía diferente (o era una mezcla entre olor a sangre y podredumbre, no estaba seguro) y al parecer solamente su figura dormida era suficiente para que Charly se sintiera amenazado, o eso presentía él: el desconocido acabaría con él apenas despertara. ¿Quién era él, dónde estaba Roy?

No sabía cómo salir del apartamento del tipo que ya no le parecía el chico dulce que conoció y que ahora le arrojaba un olor a descomposición que no notó al llegar y pasar la noche. Estaba en la cama, entre los brazos del otro, aguantando gritar y por lo que había podido ver a través de los espejos alrededor de la habitación, al pie de la cama, había trozos de carne, alambres, sangre: Charly solo pudo pensar en que sería el siguiente en aparecer en los periódicos si no hacía algo, antes de que despertara el otro. Intentó zafarse de su brazo, poco a poco.

No obstante, era demasiado tarde: por el espejo vio como lentamente se levantaba el otro. Abrió los ojos... 
